\title{
Computer assisted language learning in English language classrooms in Bosnia and Herzegovina
}

\section{Nihada Delibegović Džanić1 \& Amila Hasanspahić}

\author{
1 University of Tuzla, Bosnia and Herzegovina \\ 2Bahram-bey Madrasa, Tuzla, Bosnia and Herzegovina
}

\begin{abstract}
The paper examines the application of computer assisted language learning (CALL) in English language classes in Bosnia and Herzegovina. The research was designed as an empirical examination of the attitudes of teachers and students on the successful application of computer assisted language learning in English language classrooms in Bosnia and Herzegovina. Lack of motivation is one the problems that most teachers are faced with. There are many causes of poor motivation, but one of them is certainly the unattractiveness and dullness of traditional methods, teaching materials and resources. However, many authors with educational experience point out that the use of information technology can positively influence students' motivation and encourage them to work actively. While adults, as digital immigrants, might not use modern information technology excessively, children and teens are true digital natives, who have grown up with the latest technologies and use them with great pleasure in all aspects of their lives adapting them to their needs (Prensky, 2001). The results obtained in this research are an indicator of the current attitude of teachers and students towards these issues, but they also highlight some important necessary reforms in the field of teacher education.
\end{abstract}

Key words: computer-assisted language learning; English language classes; teachers' and students' attitudes.

\section{Introduction}

Three revolutionary moments have taken place in the development of human communication: language, writing, and printing, and each has elevated human civilization to a higher stage. We are currently witnessing a revolution in human communication, based on the development and expansion of information technology and the Internet. 
The Internet has been changing and transforming almost every aspect of society. The Internet and modern information technologies have generally changed the way people communicate, shop, take pictures, plan trips, etc. It has also influenced the way students learn and experience the teaching and learning process. However, despite the multiple benefits of the Internet and information technology in general, we are interested in their application in English language teaching.

Almost all schools in developed countries are connected to the Internet, which automatically leads to radical changes and educational reforms that involve the use of modern information technologies. This transformation is not only happening in developed and rich countries. Bosnia and Herzegovina, like many developing countries, is also following this trend.

Lack of motivation is one the problems that most teachers are faced with. There are many causes of poor motivation, but one of them is certainly unattractiveness and dullness of traditional methods, teaching materials and resources. However, many authors with educational experience point out that the use of information technology can positively influence students' motivation and encourage them to work actively and productively and be creative, as evidenced in everyday teaching practice. While adults, as digital immigrants, rarely use information technology excessively, depending on their age and life needs, children and teens are true digital natives, who have grown up with the latest technologies and use them with great pleasure in all aspects of their lives, adapting them to their needs (Prensky, 2001).

What children learn has not changed significantly, but the way they learn must change. More attention must be paid to the skills that students need to acquire throughout their education, such as critical thinking skills, problem solving, decision making, goal setting, planning, and active and self-directed learning techniques. We have to agree that today there is a significant difference between the way children learn and the way their teachers teach them. It is simply necessary for a $21^{\text {st }}$ century student to study actively and interactively, to seek information and answer questions, and to exchange views with his colleagues around the world. Therefore, the characteristics of learning and teaching in the $21^{\text {st }}$ century should be: dynamism, action, creation, changing, redefining and communicating (Stevanović, 2000; Suzić, 1999).

Modern information technologies and the Internet allow English teachers to design a whole range of activities and projects, and to bring English to the children in an innovative and engaging way. However, it is important to note that not all countries have the same conditions, so the use of Computer assisted language learning (CALL) in English language teaching is limited in some parts of the world. One such country is Bosnia and Herzegovina, where most schools do not have the basic technical requirements for using modern technologies in the classroom. However, many of these activities do 
not depend on technical predispositions in the school, as they are primarily prepared and performed outside the classroom, i.e. in the students' homes, and today almost every home has the Internet access.

CALL is not the only and exclusive method of work, but one in a number of methods, and the results depend directly on the teacher's expertise and ability to successfully combine CALL with other teaching methods. The traditional approach is not necessarily a bad approach either. Moreover, anything that has proven to be good and resulted in learning English should only be further enriched and refined with new approaches and methods of working with students. In addition, the use of modern information technology in teaching requires careful planning and elaboration of the three most important stages of applying CALL in English language teaching: teachers' and students' preparation, student performance monitoring, and finally, feedback and evaluation of the results obtained. This is not easy and therefore it is important to refer to the basic pedagogical standards without which the expected results and success could be missing or incomplete.

Considering these issues, the aim of this paper is to examine the attitude and opinion of English teachers about CALL, to what extent they apply it in their practice, and what students think about it, and to highlight the problems and challenges of its application in English language classrooms.

\section{Basic principles of Computer Assisted Language Learning}

The term CALL was agreed upon at the TESOL (Teachers of English to Speakers of Other Languages) Convention in Toronto in 1983 (Chapelle, 2001: 3). The term basically refers to the combination of technology and foreign language learning (Chapelle, 2001: 3). According to Egbert, CALL involves the use of computers for the purpose of facilitating the teaching and, in a way, of learning a foreign language (Egbert, 2005: 4). However, in a slightly older definition, Egbert \& Hanson-Smith (1999: 1) define CALL as "optimal, technology-enhanced language teaching and learning environment." Levy (1997: 1), in turn, describes CALL as "the search for and the study of applications of the computer in language teaching and learning." Beatty defines CALL as "any process in which a learner uses a computer and, as a result, improves his or her language" (Beatty, 2003: 7).

It seems that the definition of CALL changes in accordance with the device used and technology development. Today, CALL can be applied in many forms, depending on the type of device or application used to teach the language. It is believed that the most popular forms of CALL are mobile learning or mobile assisted language learning (ML or MALL) and bring your own device (BYOD) technique. 


\subsection{Four CALL components}

Egbert (2005: 5) outlines four basic components that must be considered with the application of CALL:

1. Conditions for optimal learning;

2. ESL Standards, defined in 1997 by TESOL;

3. Instructions for the application of technology for educational purposes;

4. Adaptation to National Educational Technology Standards (NETS) defined by the International Society for Technology in Education (ISTE).

\subsubsection{Conditions for optimal learning}

Each lesson should meet the requirements for optimal learning, regardless of teaching aids used. Egbert \& Hanson-Smith (1999: 3) highlight eight important general conditions for optimal learning:

a) Students have the opportunity to communicate with others in English and to understand each other.

Although students can master certain structures individually, it is believed that more effective learning takes place only when students use English actively and creatively to communicate and understand one another. Everyone who has ever studied a foreign language has had an experience in which they have successfully completed grammatical tasks, but felt helpless when trying to compose a sentence in a target language. In order in improve students' speaking and writing skills, it is necessary to involve them in interactive activities.

\section{b) Students must communicate in English.}

If classroom communication is limited to individual interaction between the teacher and individual students, the rest of the class would feel excluded. It also means we must create the milieu in which students will easily communicate both inside and outside the classroom. Students must have a reason to listen and respond to the content of the listening material.

c) Students are involved in authentic tasks.

Planning and implementing authentic tasks is the most important requirement for language learning process. An authentic task is one that students will be able to use outside of the classroom in the real world, i.e. a task that resembles a real situation outside the classroom. Even a grammar exercise can be implemented as an authentic task if students see the applicability of that activity in a real-life situation. The right task can motivate students and get their attention. 
d) Students are encouraged to produce diverse and creative linguistic expressions.

There are many individual differences in second and foreign language acquisition. Teacher should highlight the beauty of language and the possibility of expressing one's thoughts in many ways. Students should be exposed to different forms of expression in order to find their own style and way of expressing themselves easily, without fear of failure and error. work.

e) Students have sufficient time and appropriate feedback on their Some students work slower than others, and some need more or less help. It is very demanding to provide adequate feedback and allocate necessary time for each student. However, the effort invested will be rewarded in the teaching and learning process.

\section{f) Students learn with understanding.}

Students are often told what to learn but not how to learn. Although students rely on their usual habits or learning styles, they can always adopt some new ones. Optimal learning is effective learning and therefore students who understand the process will be more motivated to learn. ing.

g) Stress free environment in classroom is necessary for effective learnThe amount of positive stress or pressure that helps students to learn effectively varies from person to person. Students should feel comfortable enough to take the risk and express themselves in English, but they should certainly not be indulged in easy tasks and exercises that do not require a great deal of effort. The teacher can create optimal positive stress by matching the complexity of the activity with the students' abilities. Therefore, the task should be difficult enough to pose a particular challenge for the student, but not too difficult to accomplish.

\section{h) Allow some autonomy to the students.}

Students are often asked to follow a very rigid schedule that requires a number of exercises, lessons, modules etc. However, this approach is not always effective and sometimes requires certain modification and personalization in accordance with students' needs, their proficiency, interests and learning styles. Students should be allowed to choose a topic for a paper or project, a book to read.

Egbert (2005: 8) concludes that these eight conditions are in line with TESOL's pre-K-12 and adult ESL standards. 


\subsubsection{Integration of basic standards in English language teaching}

Basic standards for teaching English are defined by the TESOL International Association (ESL Standards for Pre-K-12 Students, TESOL, 2007), which suggests that students should be able to communicate successfully in a variety of social and academic situations, and to continue learning outside the classroom as well. These standards, as well as the conditions listed above, can be met by a variety of techniques, such as:

- playing roles that encourages active learning;

- enabling students to get in touch with people who are fluent in English;

- focusing on language rather than language learning;

- using more demanding techniques;

- using various media;

- using language with meaning and understanding;

- allocating flexible time for every task depending on its complexity;

- providing adequate feedback to the students;

- providing necessary information on resources and information needed for projects and research;

- be available to students when they have to make important decisions regarding their research or learning process in general.

\subsubsection{Instructions for using technology in teaching}

Meeting optimal conditions for learning and adapting goals and objectives to language learning standards is crucial for CALL, but this is only one segment of the process. Designing CALL activities and projects, the teacher must consider the role of technology in supporting effective learning. Egbert (2005: 11) outlines five basic instructions that a teacher must keep in mind when applying CALL. Similar guidance can be found in other available literature on the application of modern technologies in teaching in general, not just to English language teaching.

- The use of technology must be consistent with the pedagogical aims of the lesson and curriculum. In other words, contemporary teaching technologies should not be used solely for the sake of formality. Although IT literacy is of paramount importance today, technology must still be subordinated to the pedagogical and methodological aims of the curriculum. Every application of technology must be carefully planned to meet the desired results.

- Technology must meet everyone's needs. Our students are individuals with different learning styles, experiences, interests and needs. Therefore, 
CALL activities should be designed for different types of intelligence and learning styles. For example, some students prefer visual activities, while others prefer verbal ones. Therefore, the activities should be diverse and provide the student with different opportunities that will eventually develop different skills. Repeated activities, however effective and interesting, do not always suit everyone. More proficient students will be bored and activity will lose its importance.

- Technology should only be used as a teaching tool. The computer, despite its many capabilities, does not replace the teacher. It is true that there are smart applications by which the learner can learn and practice certain structures, thus contributing to easier and more optimal learning. However, the exercises themselves are not enough to teach a language. Therefore, no technology can replace the role of the teacher, their guidance, monitoring the students' work and, ultimately, their assessment and evaluation. It is best to consider technology as a teaching tool that supports the teaching process in many ways.

- Technology should be applied effectively. It means that students can learn better and faster with wise application of technology. For example it will be almost impossible for a teacher to simultaneously check their students' answers in activities like fill in the gaps, cloze test, multiple choice. If students do the same exercise on their computers they will receive instant feedback that might not be creative as the one provided by their teachers, but certainly will be informative enough.

- Technology should be applied efficiently to achieve the aims of the lesson in less time. For example, a student can quickly and easily find audio and video material that they can access when they want with just one click. Finding and listening to such material in the old-fashioned way is difficult and time-consuming. All these instructions should be taken into account and adapted in accordance with the students learning styles, language proficiency, topic and aims of the lesson.

\subsubsection{Integrating National Educational Technology Standards (NETS)}

According to the International Society for Technology in Education (ISTE), in addition to the above-mentioned standards and guidelines, the teacher must strive to comply with national standards for the application of educational technologies so that students who complete school are, among other things, computer literate. Therefore, every student at the end of compulsory secondary education should be able to:

- use a computer and other information technologies;

- use modern technologies responsibly and critically; 
- access electronic sources in an appropriate manner;

- plan, implement and publish completed tasks and projects;

- collect information;

- cooperate with others.

These standards are in line with TESOL standards, guidelines for the use of technology in teaching and with the optimal learning conditions we mentioned earlier, and they complement and confirm each other.

\section{Results of the research on computer assisted learning in English language classrooms in Bosnia and Herzegovina}

\subsection{Method}

Undoubtedly, modern information technologies are being imposed on us every day inside and outside classrooms. In the previous part we presented several examples of the successful application of modern technologies in the English language classroom. However, the question is to what extent these technologies are used and what teachers and students think about it in Bosnia and Herzegovina, a country where schools often do not meet even the most basic technical and technological conditions for work and where the socio-economic situation is at a very low level.

The research was designed as an empirical examination of the attitudes of teachers and students on the successful application of computer assisted learning in English language classrooms in Bosnia and Herzegovina. The results obtained are an indicator of the current attitude of teachers and students towards these issues, but they highlight some important necessary reforms in the field of teacher education. The following research questions are central to the empirical part:

(1) Do teachers and students in Bosnia and Herzegovina view information technology as a motivating factor in education?

(2) Do teachers and students consider that modern information technologies improve English language skills?

(3) Does the application of modern information technologies facilitate the teaching process both for teachers and students?

(4) Is it possible in our schools to successfully plan and implement CALL regardless of the equipment availability?

(5) What activities have already been implemented by students and teachers with the help of modern information technologies in order to determine the extent to which this inexhaustible source of activities and projects has been utilized and how diverse they are? 
Nihada Delibegović Džanić \& Amila Hasanspahić: Computer assisted language learning in English language classrooms in Bosnia and Herzegovina

In accordance with the above-mentioned research questions, the research was conducted on a sample of 150 students from 6 secondary schools in Tuzla Canton and 60 teachers from 27 different cities across Bosnia and Herzegovina.

\subsection{Analysis and interpretation of results}

\subsubsection{Teacher survey}

The main aim of this research is to examine teachers' attitudes towards the use of modern information technologies in teaching English. Their attitudes are formed on the basis of experience in working in different conditions with primary and secondary school children that have different language proficiency. The survey was conducted using a Likert summation scale, on which the respondent has the ability to clearly express a positive or negative view of CALL and its application in the teaching process. Respondents were given the opportunity to specify their level of agreement to a statement typically in five points from expressly accepting the claims as always true, often true, partly true, rarely true, to outright rejection. The last two questions are openended.

We believe that this form is sufficient to differentiate the respondents and to understand the general attitudes towards CALL, that is, the application of modern information technologies in English language classroom.

\subsubsection{Distribution of teachers' attitudes in Bosnian and Herzegovinian schools}

Respondents were asked for each statement to indicate their value attitude with a score of 1-5, where 1 means never, 2 rarely, 3 sometimes, 4 very often, 5 always.

Claim no. 1: Students learn English more effectively when they are actively involved in a task and when they can apply all the acquired knowledge and skills to solve it.

Most of the surveyed teachers in the percentage of $70 \%$ absolutely agree with this claim that this is always the case, $26.67 \%$ think it is a very common case and only $3.33 \%$ think it is only sometimes so. None of the teachers interviewed expressed the view that active involvement and participation in the project had no significant or no effect on learning outcomes. This attitude indicates that teachers notice better results when students are confronted with a task in which they must apply a range of knowledge and skills to solve it. In comparison to classical memorization students learn easier and faster, almost unobtrusively, new vocabulary and structures. These new forms are recycled in the activities and tasks and therefore it is more likely that learners will memorize them. 
Nihada Delibegović Džanić \& Amila Hasanspahić: Computer assisted language learning in English language classrooms in Bosnia and Herzegovina

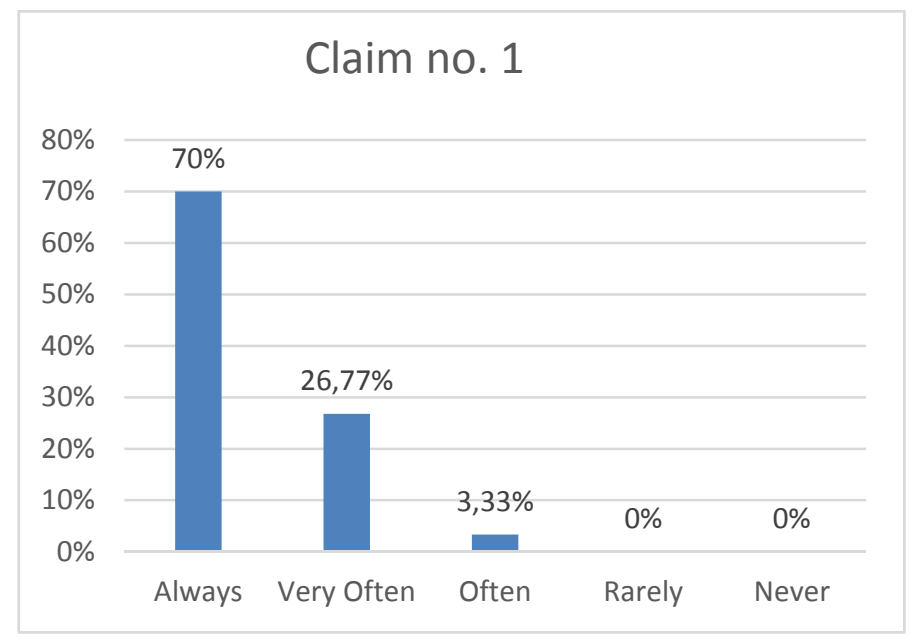

Figure 1: Students learn English more effectively when they are actively involved in a task and when they can apply all the acquired knowledge and skills to solve it.

Claim no. 2: Motivated students achieve better results.

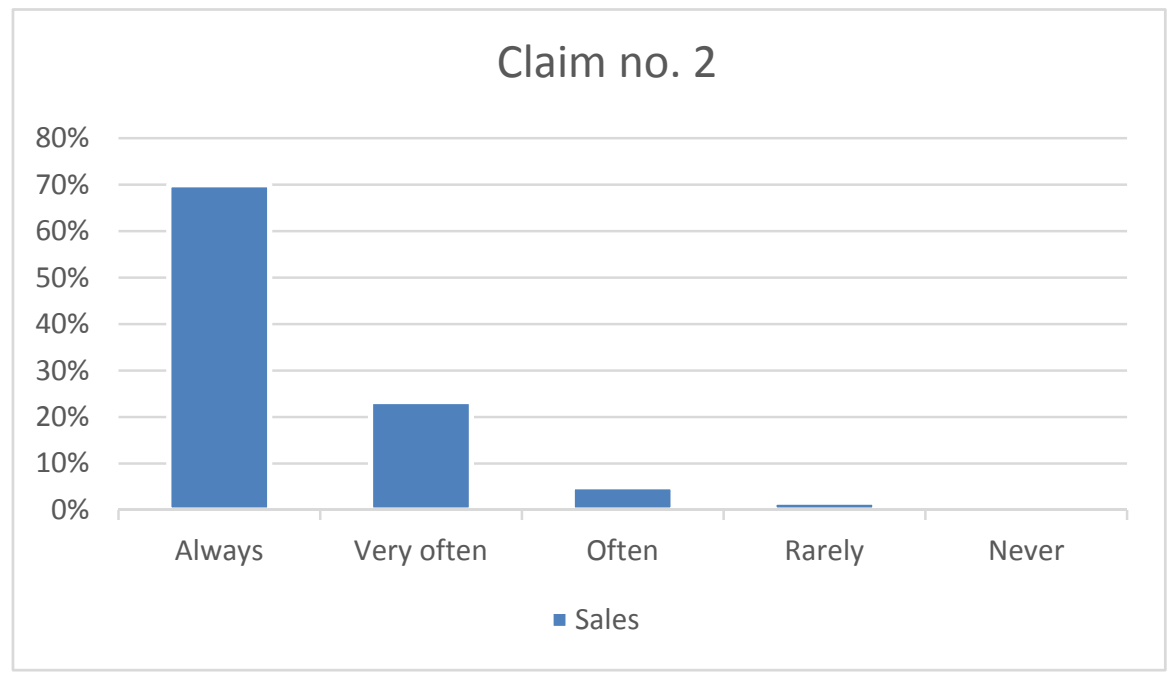

Figure 2: Motivated students achieve better results. 
When it comes to motivation, $70 \%$ of teachers surveyed think that motivated students always achieve better results, $23.33 \%$ think that motivation often plays an important role, $5 \%$ think that sometimes it plays a role, while only $1.67 \%$ think that motivation rarely needed to acquire knowledge and achieve good results. None of the respondents stated that they completely disagree. The teachers, with their strong acceptance of the second claim showed that motivation is a necessary factor in education, and that lack of motivation has a negative impact on their students' success. The teacher must constantly find new and creative ways to motivate students to achieve the aims of the lessons. CALL or the use of modern information technology in teaching English is an inexhaustible source of student motivation.

Claim no. 3: Students eagerly use new technologies in class and extracurricular activities.

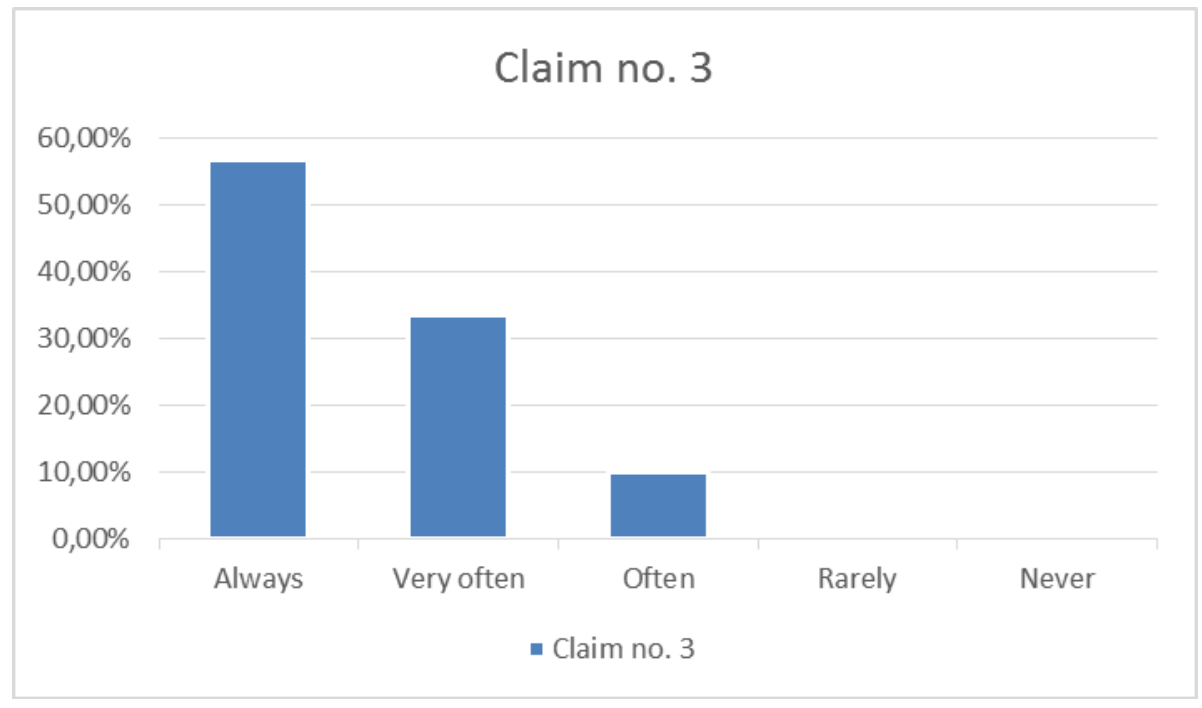

Figure 3: Students eagerly use new technologies in class and extracurricular activities.

As expected, $56.67 \%$ of teachers believe that their students eagerly use modern information technologies in class and extracurricular activities, $33.33 \%$ state that they very often find student approval, while $10 \%$ sometimes notice such a reaction from their students. This attitude shows that we have to be moderate with everything, and that excessive use of these technologies can produce fatigue and boredom for students. Also, this can be an indicator that these activities performed with the help of modern infor- 
mation technologies have not been well planned or implemented and, therefore, could not have encountered student enthusiasm and approval.

Claim no. 4: I apply CALL whenever I can.

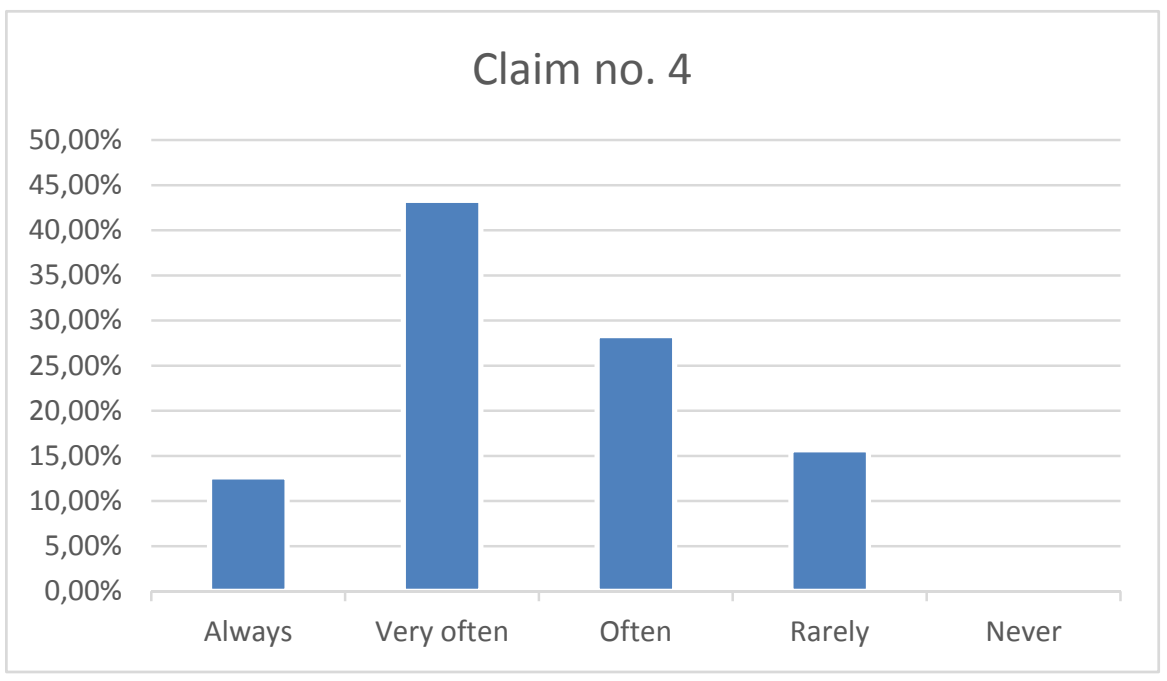

Figure 4: I apply CALL whenever I can.

The results have shown that $12.67 \%$ of teachers who participated in this survey state that they constantly apply modern information technologies in their classrooms, $43.33 \%$ do it very often, $28.33 \%$ sometimes do this kind of activity with their students, while $15.67 \%$ rarely do it. None of the respondents expressed a negative opinion on this matter, claiming that they never use a computer and the Internet in teaching.

\section{Claim no. 5: CALL can enhance students' motivation and enthusiasm}

According to the results obtained $30 \%$ of teachers claim that CALL always motivates students, $55 \%$ state CALL is very often a motivating factor for students, and $15 \%$ point out that CALL sometimes affects motivation and students' enthusiasm for learning English. Teachers have shown that they recognize modern information technologies as a powerful motivating factor for learners who are overburdened with extensive and dry material and facts they must remember. 
Nihada Delibegović Džanić \& Amila Hasanspahić: Computer assisted language learning in English language classrooms in Bosnia and Herzegovina

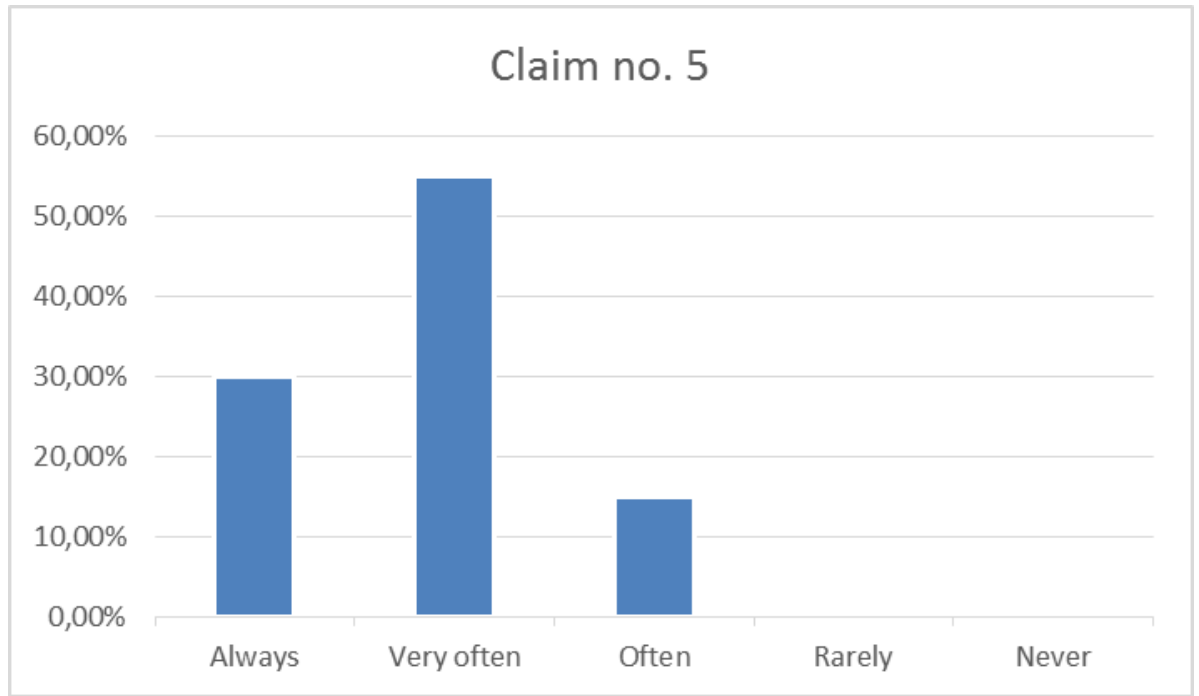

Figure 5: CALL can enhance students' motivation and enthusiasm.

Claim no. 6: CALL enables authentic language learning.

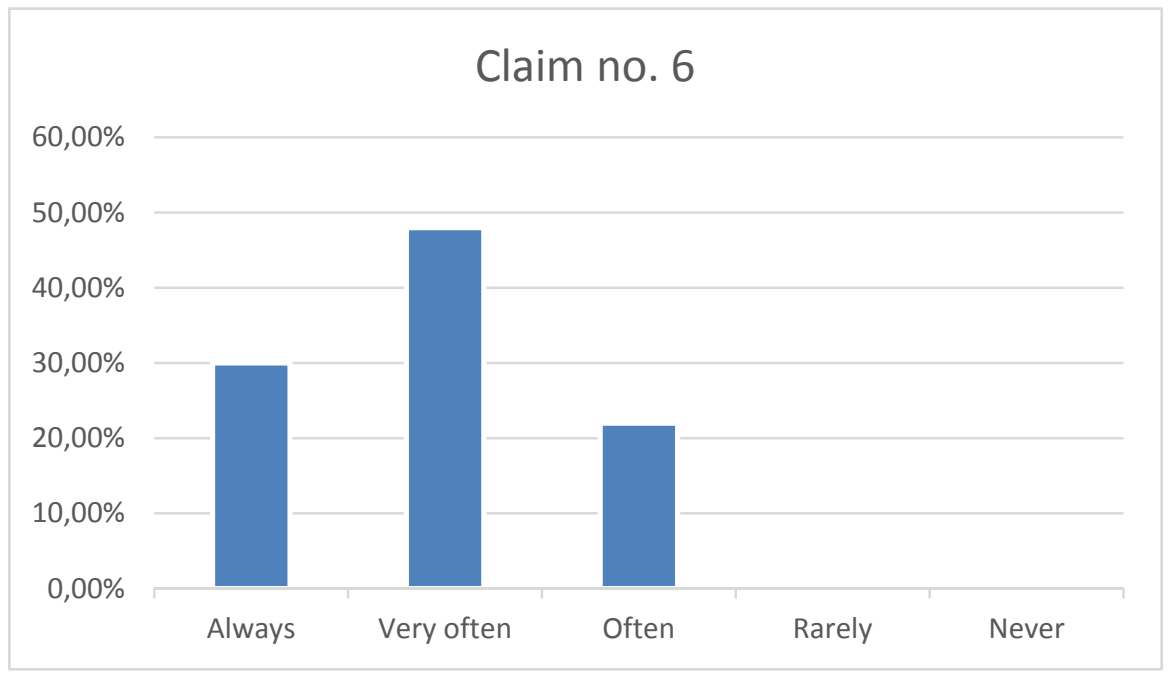

Figure 6: CALL enables authentic language learning.

English teachers in Bosnia and Herzegovina are struggling with the fact that their students are not exposed enough to authentic materials. Therefore, 
it is not surprising, that $30 \%$ of respondents believe that CALL is always a source of authentic English learning experience. For $48 \%$ of respondents CALL enables authentic English language learning in majority of activities, while $22 \%$ believe that this is sometimes the case. None of the respondents had a negative attitude towards this issue. This is a clear indication that teachers are aware of the fact that students can access authentic materials using CALL, which provides many learning opportunities for students.

Claim no. 7: CALL makes the learning process more interesting and effective.

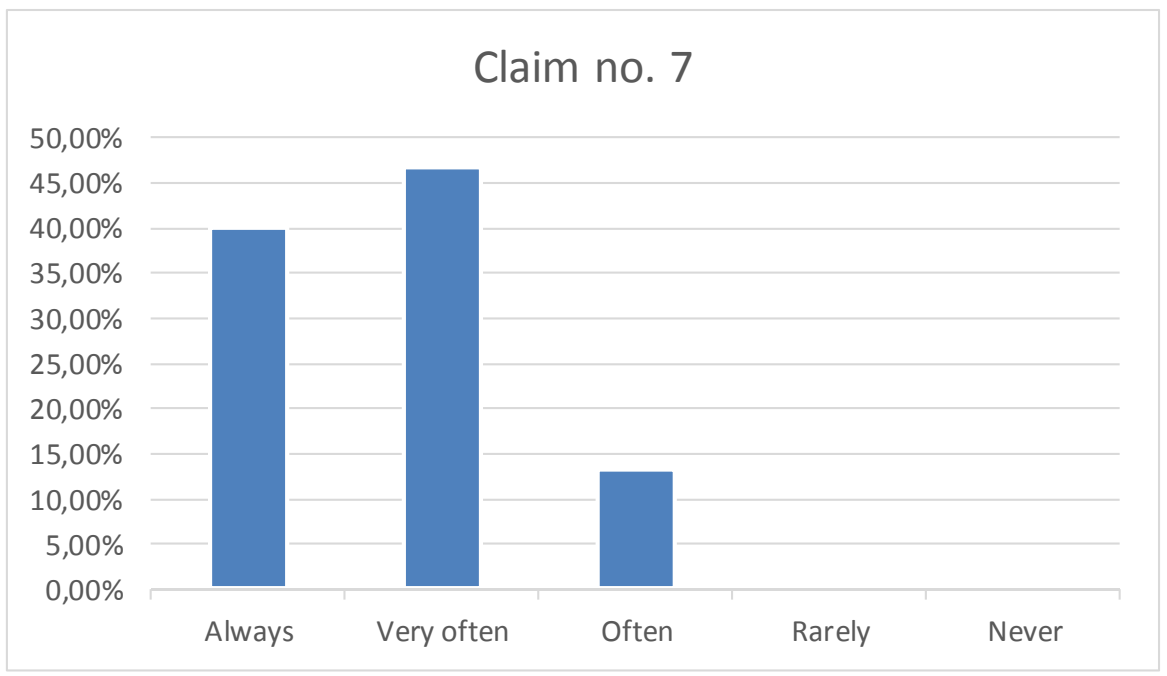

Figure 7: CALL makes the learning process more interesting and effective.

$40 \%$ of the teachers surveyed believe that CALL always makes the process of learning English more interesting and effective, $46.67 \%$ of them believe that, in comparison to traditional methods, CALL sparks more interest, while $13.33 \%$ sometimes notice such effect of CALL in their students. Again, no respondents had a negative attitude towards the efficiency of using computers and the Internet in teaching English.

Claim no. 8: CALL is integrated into the curriculum without any obstacles.

The respondents rated this statement differently, which confirms that there are some difficulties in the application of CALL in teaching English. $18.33 \%$ always successfully integrate CALL into the curriculum without any problems, $25 \%$ very often successfully implement it, $40 \%$ sometimes experi- 
ence certain problems, $13.33 \%$ are rarely successful in the application of CALL, while $3.33 \%$ have severe problems and never successfully integrate CALL into their curriculum.

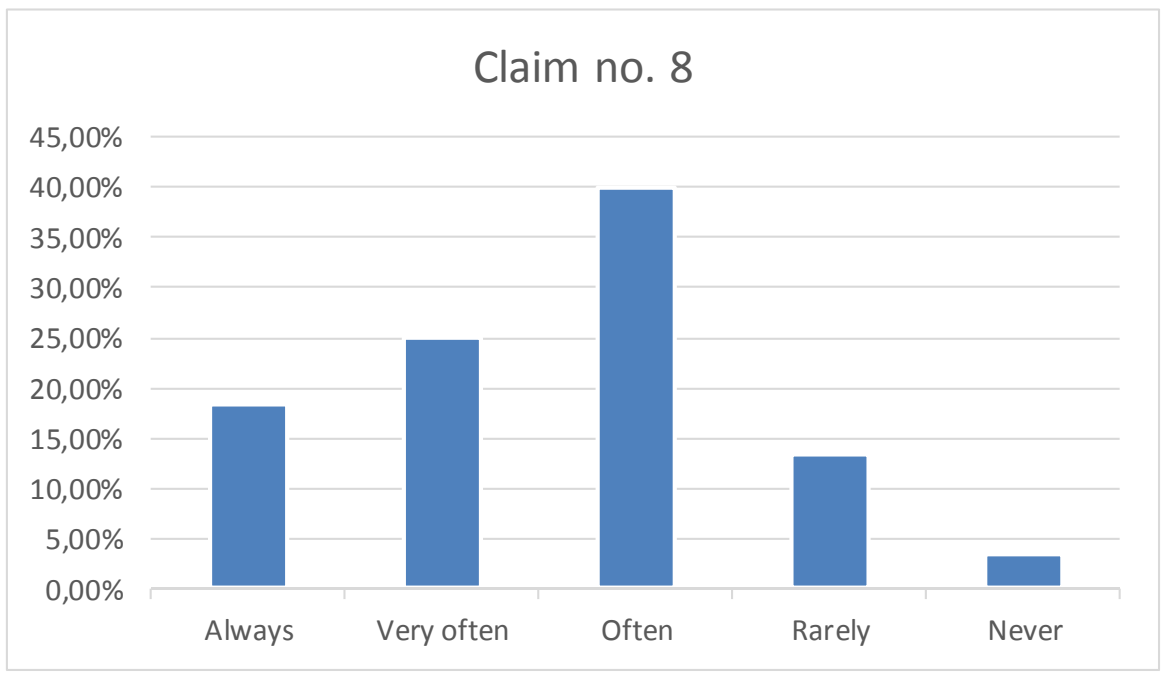

Figure 8: CALL is integrated into the curriculum without any obstacles.

This value proposition speaks to the fact that the computer literacy of the English language teachers is at a high level and that modern information technologies can be integrated into their classes without major problems. Sporadic problems are not uncommon because, with or without information technology, the teaching process is very complex and the teacher is constantly confronted with the problems and need to change and adapt methods and ELT materials. Significant problems with the integration of CALL into the curriculum can be avoided with adequate teacher education in line with technological advances in the times we live and work.

\section{Claim no. 9: CALL requires a lot of time both from teachers and students}

It is interesting that respondents are divided on this point. $13.33 \%$ of the teachers surveyed claim that CALL always takes a lot of time, $18.33 \%$ often have to devote a lot of time to CALL, 55\% of respondents sometimes need a lot of time, and $13.33 \%$ rarely spend a lot of time on CALL activities. It must be borne in mind in almost all schools in Bosnia and Herzegovina we have large heterogeneous classes, which often makes any activity more demanding and more time is required for its preparation and implementation. This 
Nihada Delibegović Džanić \& Amila Hasanspahić: Computer assisted language learning in English language classrooms in Bosnia and Herzegovina

may also indicate that we need to carefully plan and choose activities so that they are effective and practical, and that they do not take much time for either the teacher or the student. But it is certainly important to emphasize that every successful activity requires effort and time, and the result achieved will be worth the effort and time invested.

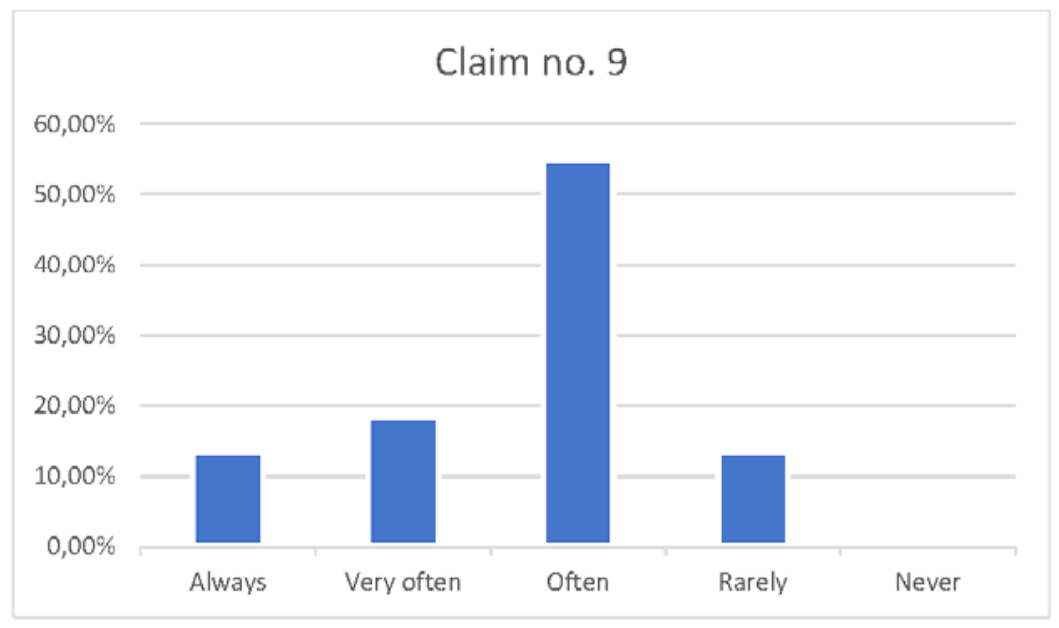

Figure 9: CALL requires a lot of time both from teachers and students.

Claim no. 10: CALL is difficult to apply in large heterogeneous classes

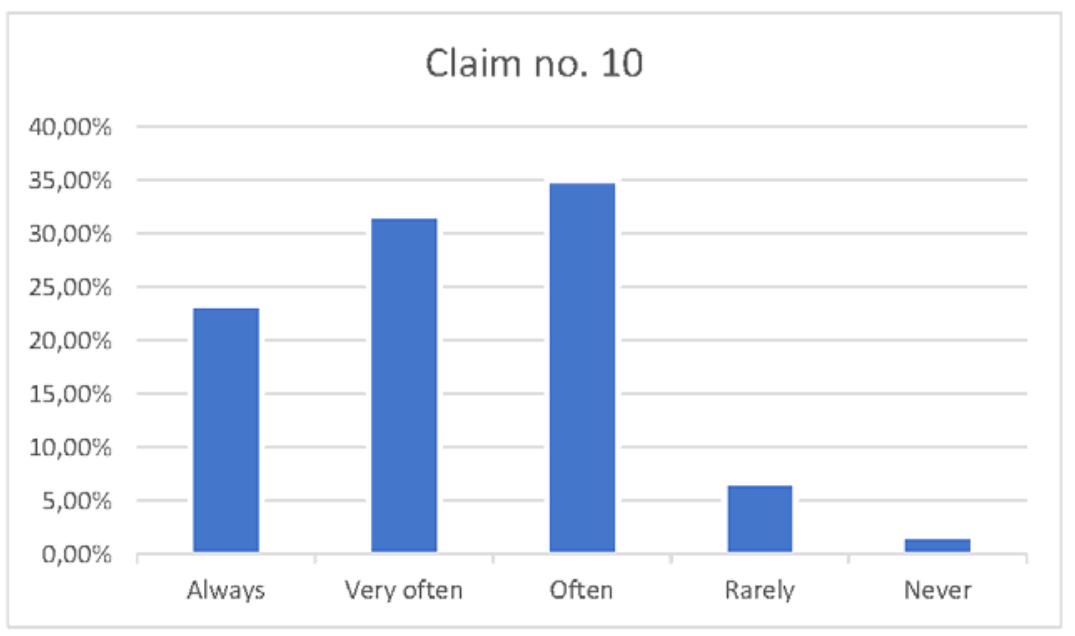

Figure 10: CALL is difficult to apply in large heterogeneous classes. 
Large heterogeneous classes are always a problem for a successful implementation of CALL for $23.33 \%$ of respondents, $31.67 \%$ of them consider it a very common problem, for $35 \%$ of respondents it is an occasional challenge, $6.67 \%$ of them rarely find it as an obstacle and $1.67 \%$ of respondents do not perceive as a problem to apply CALL in large mixed-ability classes.

Claim no. 11: Careful planning and preparation is crucial for the successful implementation of CALL.

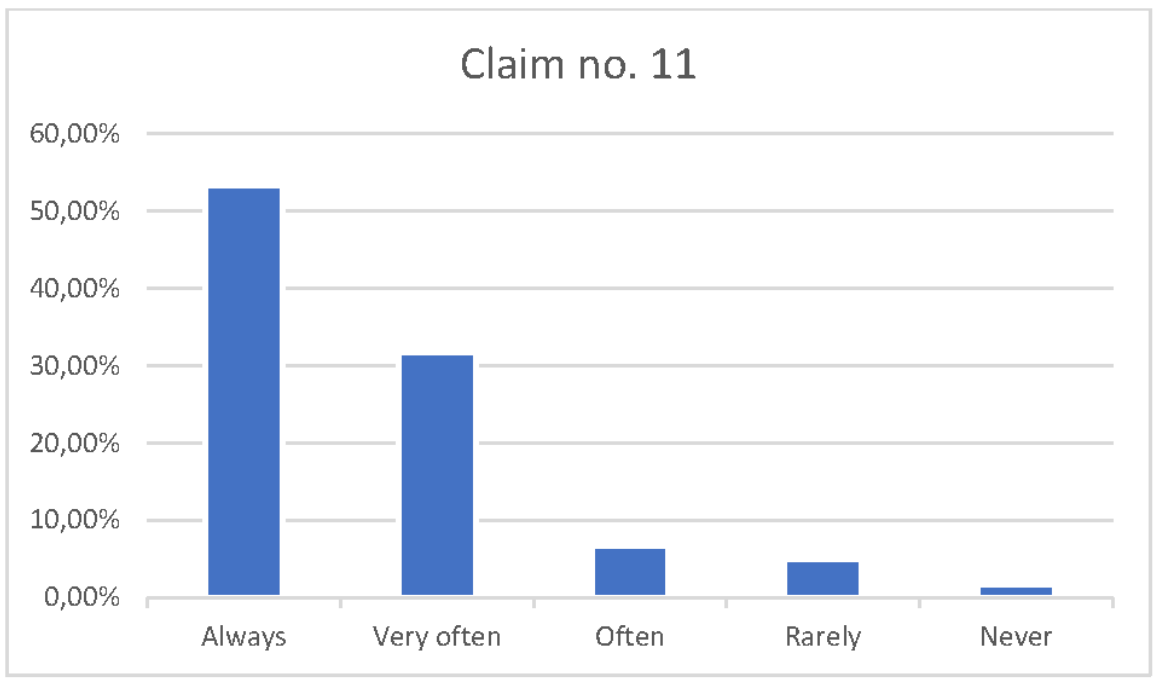

Figure 11: Careful planning and preparation is crucial for the successful implementation of CALL.

Large mixed-ability classes represent a challenge for teachers of all fields and require a lot of creativity for all activities, not just CALL. But, in all professional development seminars, one can hear about the adaptation of ELT materials to all levels and abilities of students, and that we must always find the tasks for the weakest and most talented students in the class. The same is valid for CALL. This confirms our claim that more education is needed in this area to present the diverse use of computers and the Internet to the teachers. Ideally these activities should not be difficult for even the weakest students and at the same time not too easy for even the most talented students. Just like traditional methods CALL also offers different types of activities from individual to group work. Experienced teachers know that activities could be assigned in accordance with the level of difficulty so that all students will be kept occupied in activities suitable for their level of profi- 
ciency. This arrangement would be also challenging for talented students who are always motivated for this kind of work and who can answer almost any imaginable task.

Respondents showed a strong agreement with this statement. 53.33\% consider planning and preparation a crucial factor for the success of CALL, $31.67 \%$ consider planning a very common success factor for CALL, while $6.67 \%$ respondents consider it an occasional success factor. For $5 \%$ of teachers preparation and planning is rarely important, and $1.67 \%$ of respondents do not consider it an essential factor for CALL performance.

Claim no. 12: CALL activities are easy to evaluate.

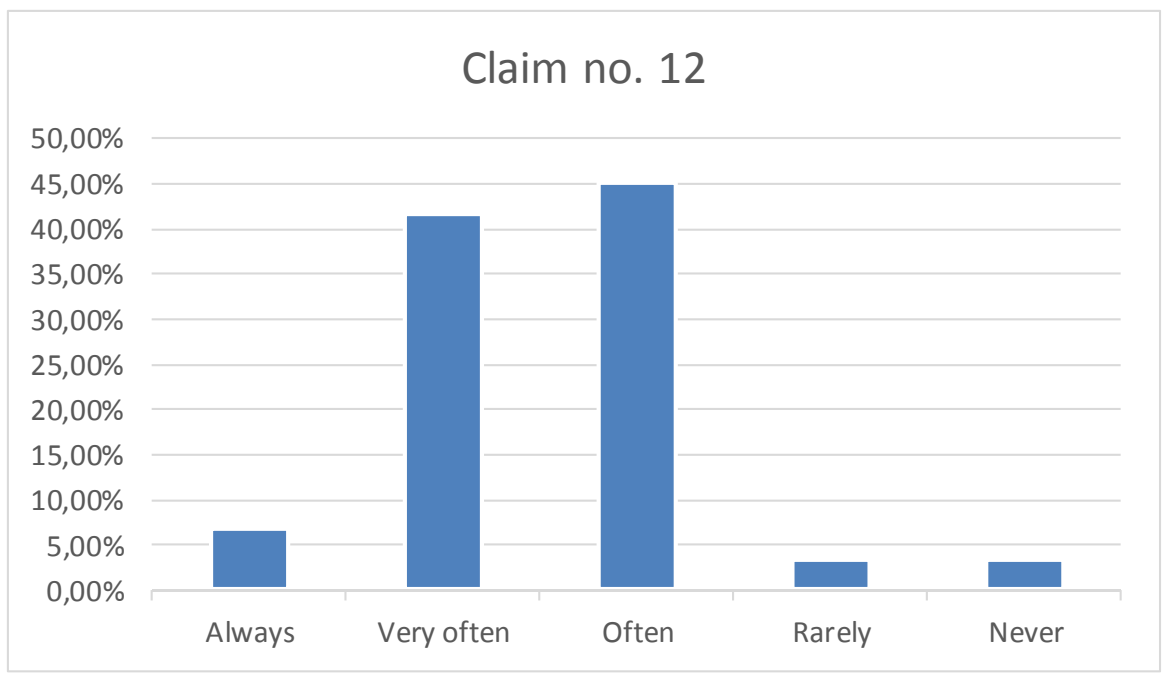

Figure 12: CALL activities are easy to evaluate.

Students expect appropriate assessment for everything they do, and teachers find it often difficult to evaluate students' effort in CALL activity. Respondents expressed themselves as follows: $6.67 \%$ of respondents think that it is always difficult to assess students, $41.67 \%$ think that it is very often difficult to evaluate students' work, $45 \%$ of teachers surveyed believe that it is sometimes difficult, $3.33 \%$ that it is rarely the case and 3.33\% that it is never difficult to evaluate a CALL activity. 
Nihada Delibegović Džanić \& Amila Hasanspahić: Computer assisted language learning in English language classrooms in Bosnia and Herzegovina

Claim no. 13: The school I work at is well equipped for CALL.

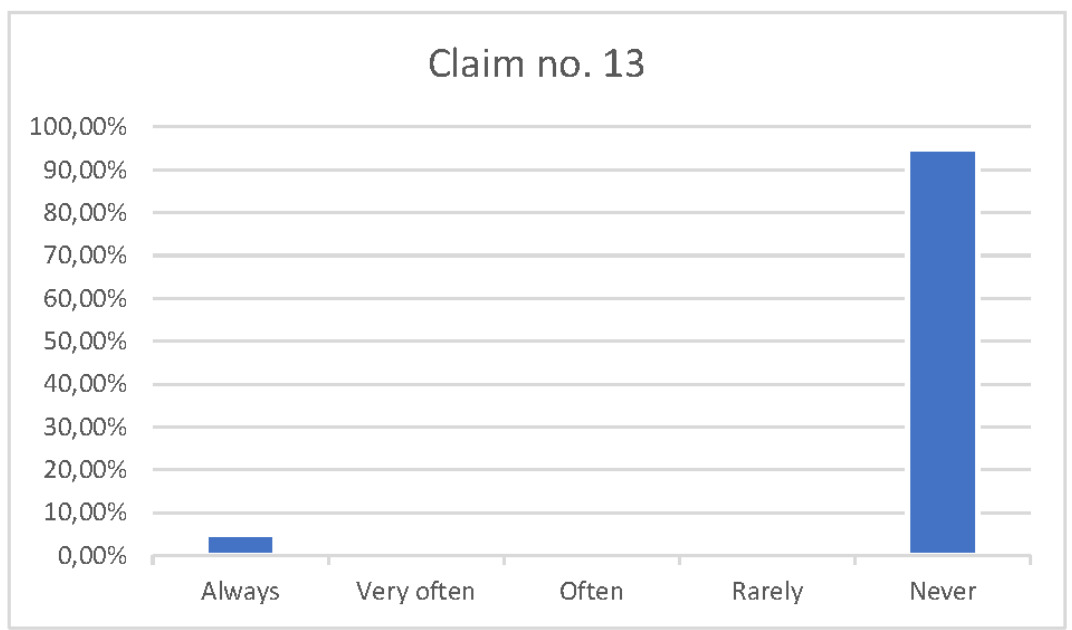

Figure 13: The school I work at is well equipped for CALL.

Understandably, teachers who work in non-mainstream schools are in the majority. 95\% of respondents say they work in schools that have no or little technological equipment or to implement CALL at school, while only $5 \%$ work in well-equipped schools. This leads us to the conclusion that CALL is difficult to perform in such an environment, not to mention the time management in the class. It is necessary to bring out activities outside the school walls and think outside the box. However, this leads directly to the question of whether there are good CALL conditions in the home environment at all.

Question no. 1: What are the greatest problems you face in the application of CALL in teaching?

The respondents mentioned the following problems in working with students with the help of modern information technologies:

- poor technological equipment and Internet connection in schools;

- lack of the Internet and computers in students' homes;

- lack of time;

- extensive study programs that must be implemented;

- large classes;

- unreliable information on the Internet;

- students are not used to this type of learning;

- low digital literacy of students and teachers; 
- use of native language during the activity.

Question no. 2: List some of the activities you have accomplished with your students with the help of modern information technology.

Teachers surveyed stated that they often carry out the following activities with their students:

- power point presentations;

- watching films, cartoons and other videos;

- students' own videos on a given topic;

- writing short stories;

- teaching vocabulary and grammar;

- mind maps;

- research on various topics (healthy food, ethical issues, sociology, biology, religion, etc.)

- website creation;

- skype communication with students in other countries;

- digital storytelling;

- video games;

- making a documentary based on a story;

- interactive video.

$28.33 \%$ of the respondents did not comment on the activities they carry out with their students, while the majority of those who answered this question mentioned only one to two activities. This leads us to the conclusion that CALL is still underrepresented in our schools, and there is a real need to educate teachers in this matter.

\subsubsection{Student survey}

The primary aim of this research is to examine students' attitudes towards the use of modern information technologies in learning, with particular reference to their application in English language learning. Attitudes of students are formed on the basis of their experience in school but also habits of using modern technologies outside the classroom. Within this research, 150 students from the following six secondary schools were examined: Behrambey Madrasa in Tuzla, Grammar School "Mustafa Novalić" Gradačac, Vocational High School Kalesija, Grammar School "Dr. Mustafa Kamarić" Gračanica, Vocational High School Živinice and Vocational High School Sapna. Students attending these schools belong to different social backgrounds. These are students in grades 3 and 4 of high school and their age is between 17 and 19. Also, their grades and success at school differ, which 
speaks in favor of the diversity of the respondents, and thus the objectivity of the survey itself.

The survey was conducted by means of a questionnaire in which the respondents had the opportunity to clearly express a positive or negative attitude regarding modern information technologies and their application in education in general, as well as in learning English. The last two questions were open-ended. It is believed that this form is sufficient to differentiate the respondents and to understand the general attitudes of the students towards modern information technologies in the education and learning of English.

\subsubsection{Distributing students' attitudes}

The Student Survey consists of twelve questions. The first ten questions are close-ended questions as respondents could choose one of the offered answers. The last two questions are open-ended.

Question no. 1: Which of these devices do you own?

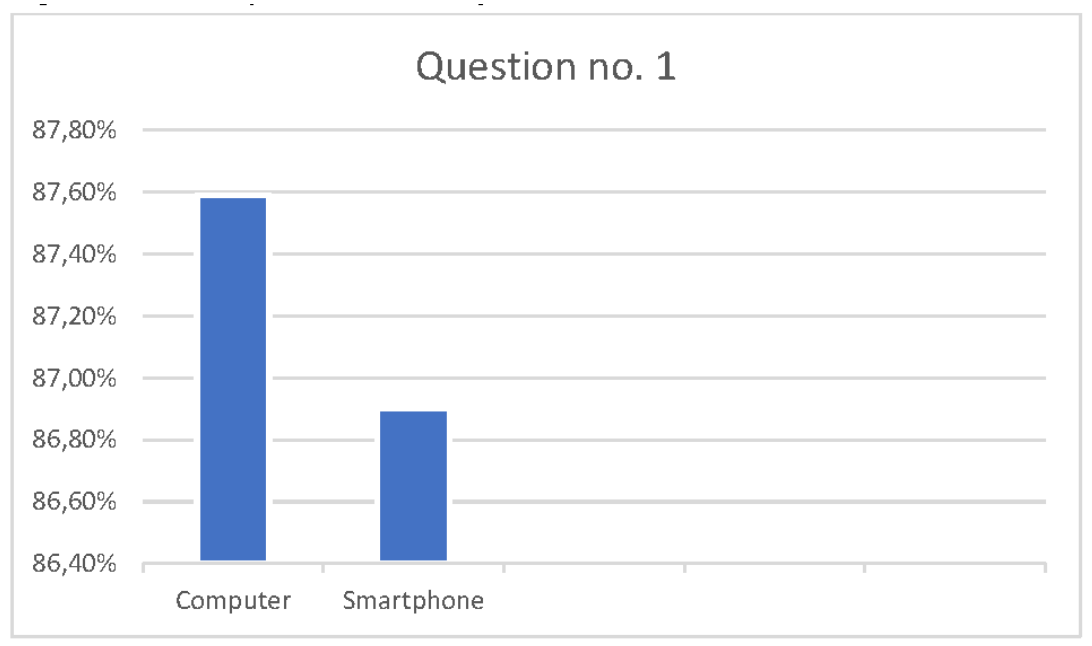

Figure 14: Which of these devices do you own?

$87.59 \%$ of respondents said they owned a computer, while $86.90 \%$ said they owned a smartphone. Analyzing the answers of $12.41 \%$ of respondents who do not have a computer, we came to the conclusion that everyone has a smartphone, while $13.10 \%$ who do not have a smartphone own a computer. This tells us that at least one type of modern information technology is available to all students who have the ability to connect to the Internet. 
Nihada Delibegović Džanić \& Amila Hasanspahić: Computer assisted language learning in English language classrooms in Bosnia and Herzegovina

Question no. 2: Do you have Internet access in your home?

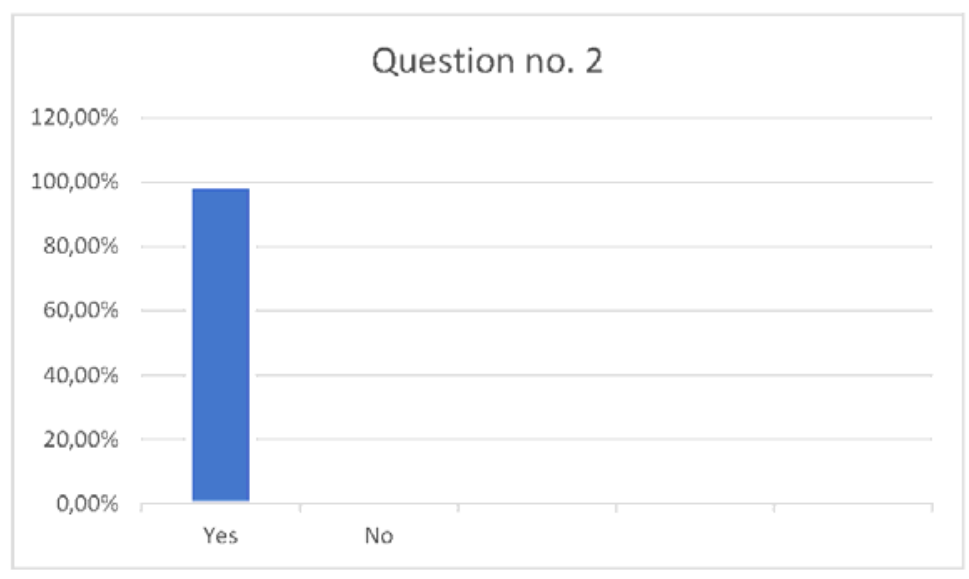

Figure 15: Internet access.

$98.62 \%$ of respondents have Internet access in their homes, while only $1.38 \%$ do not have this option. This information refutes teachers' claims that their students do not have good conditions for the application of modern information technologies and the Internet to complete their tasks and projects. This claim was the most cited reason for the poor application of the mentioned technologies in teaching and extracurricular activities.

Question no. 3: How often do you use the Internet?

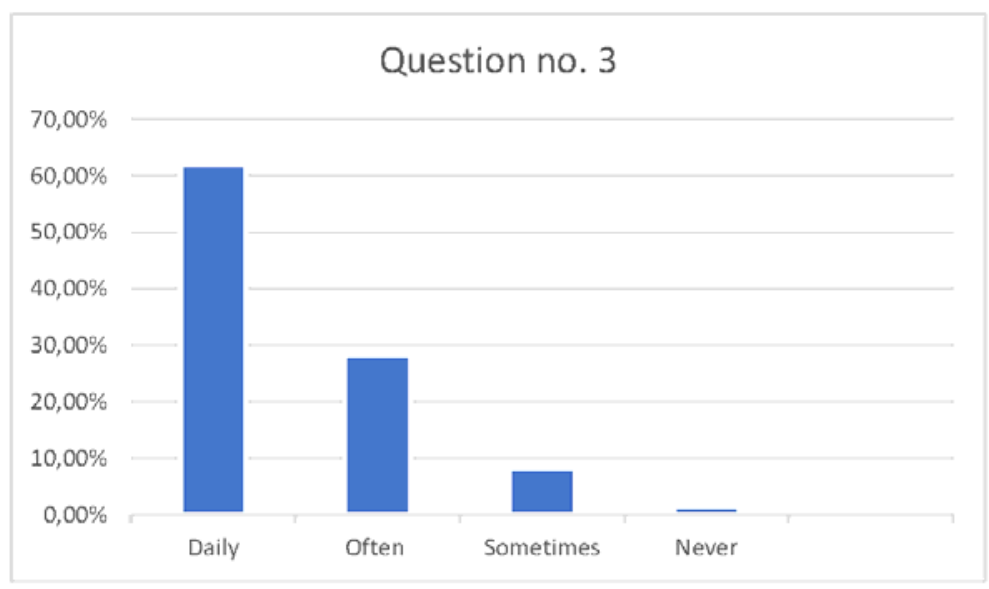

Figure 16: Internet usage frequency. 
Nihada Delibegović Džanić \& Amila Hasanspahić: Computer assisted language learning in English language classrooms in Bosnia and Herzegovina

$62.07 \%$ of respondents claim to access the Internet daily via a smartphone, laptop or computer. $28.28 \%$ often use the Internet, $8.27 \%$ do so sometimes, while $1.38 \%$ say they never use the Internet.

Question no. 4: How often do your teachers use the Internet and other modern information technologies as one of the teaching aids or ways to improve their students' knowledge?

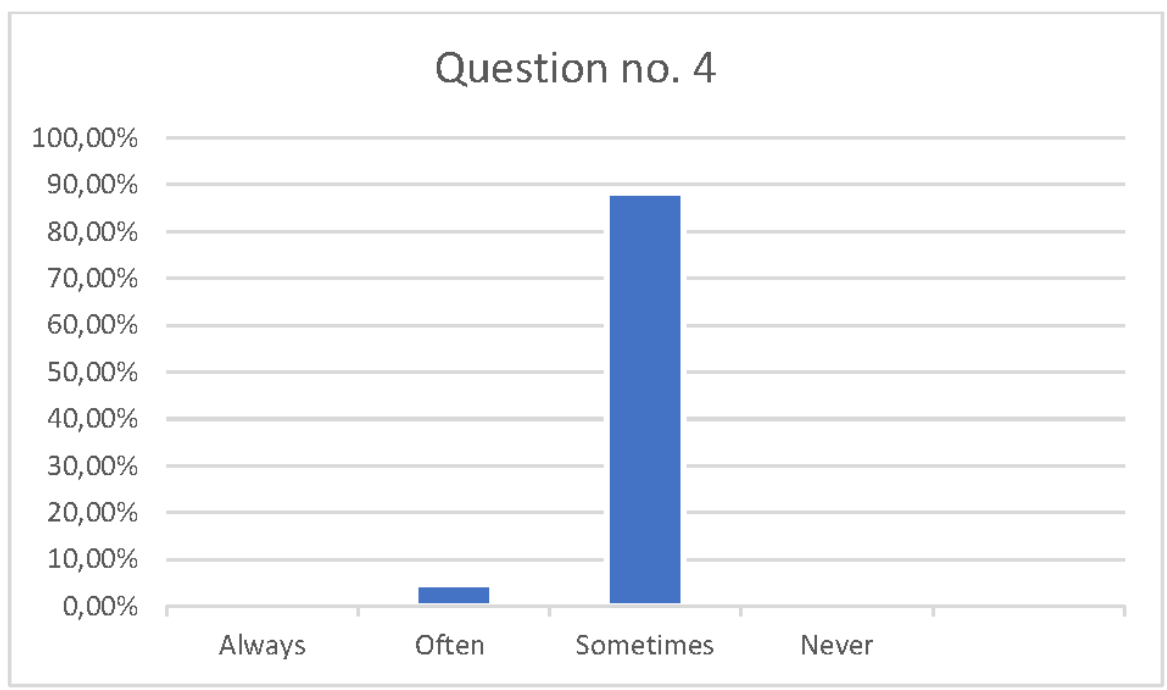

Figure 17: Teachers use modern information technologies to improve their students' knowledge.

$4.83 \%$ of the students surveyed said that their teachers often use modern information technologies in teaching and extracurricular activities, $88.28 \%$ of the respondents said that their teachers sometimes do, while $6.89 \%$ claim that their teachers never do so.

Question no. 5: Do you apply modern information technology for research, learning and education in general? 
Nihada Delibegović Džanić \& Amila Hasanspahić: Computer assisted language learning in English language classrooms in Bosnia and Herzegovina

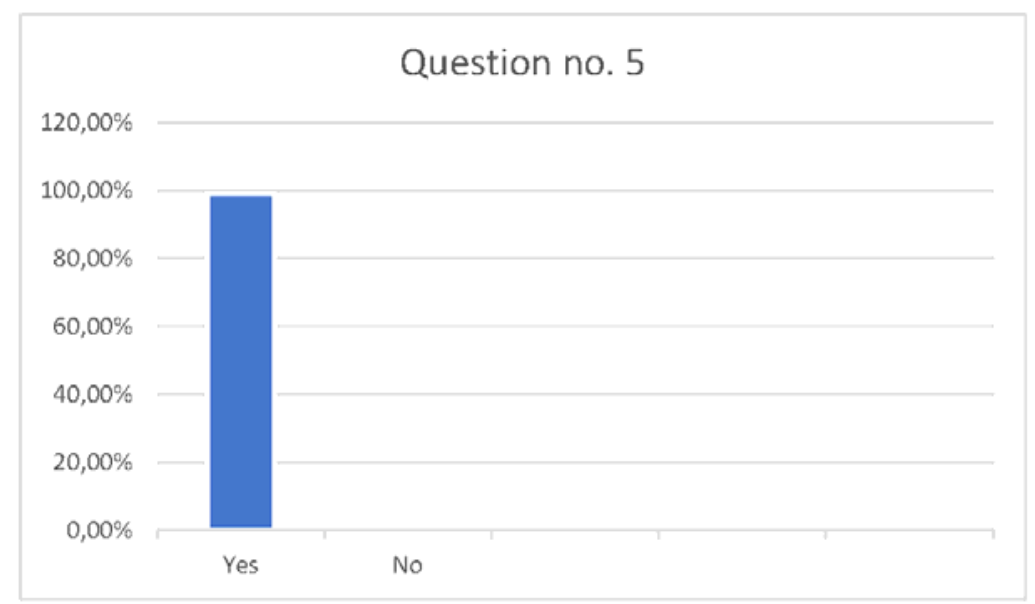

Figure 18: Application of modern information technology for research, learning and education.

$99.31 \%$ of the students surveyed do so, while only $0.69 \%$ of respondents declare that they do not apply it.

Question no. 6: Do you find the Internet and other modern information technologies useful for learning and improving knowledge and skills?

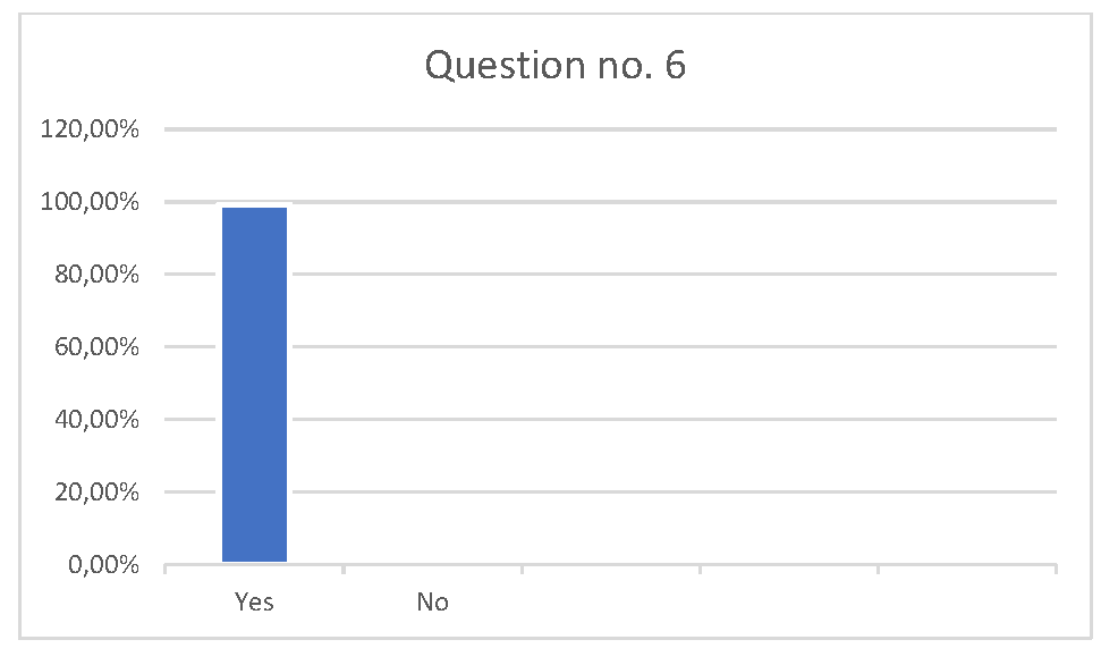

Figure 19: Internet and technologies are useful for learning and improving knowledge and skills. 
Nihada Delibegović Džanić \& Amila Hasanspahić: Computer assisted language learning in English language classrooms in Bosnia and Herzegovina

99.31\%students surveyed affirmatively answered this question, while $0.69 \%$ of respondents did not consider the Internet and technologies particularly useful for education.

Question no. 7: Do you find it easier, faster and more interesting to study and work on projects with the help of modern information technologies?

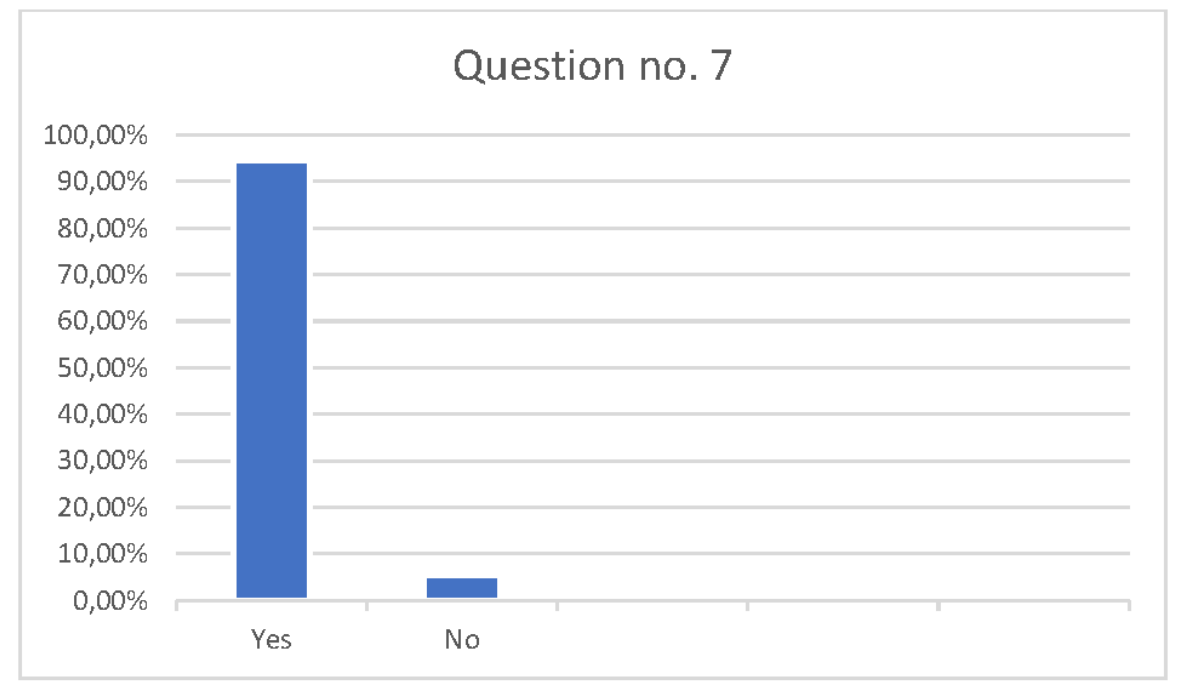

Figure 20: Modern information technologies make studying and project development easier and more interesting.

$94.48 \%$ of the students surveyed believe that modern information technologies make studying and project development easier and more interesting, while $5.52 \%$ do not find it easier to study and work on projects with the help of modern information technologies and they also do not think that CALL would make their education more interesting than it is. This may also indicate low information literacy and some individuals' lack of knowledge in the application of modern information for the purpose of learning, researching and acquiring new knowledge and skills.

Question no. 8: Do you apply modern information technology in English language learning? 
Nihada Delibegović Džanić \& Amila Hasanspahić: Computer assisted language learning in English language classrooms in Bosnia and Herzegovina

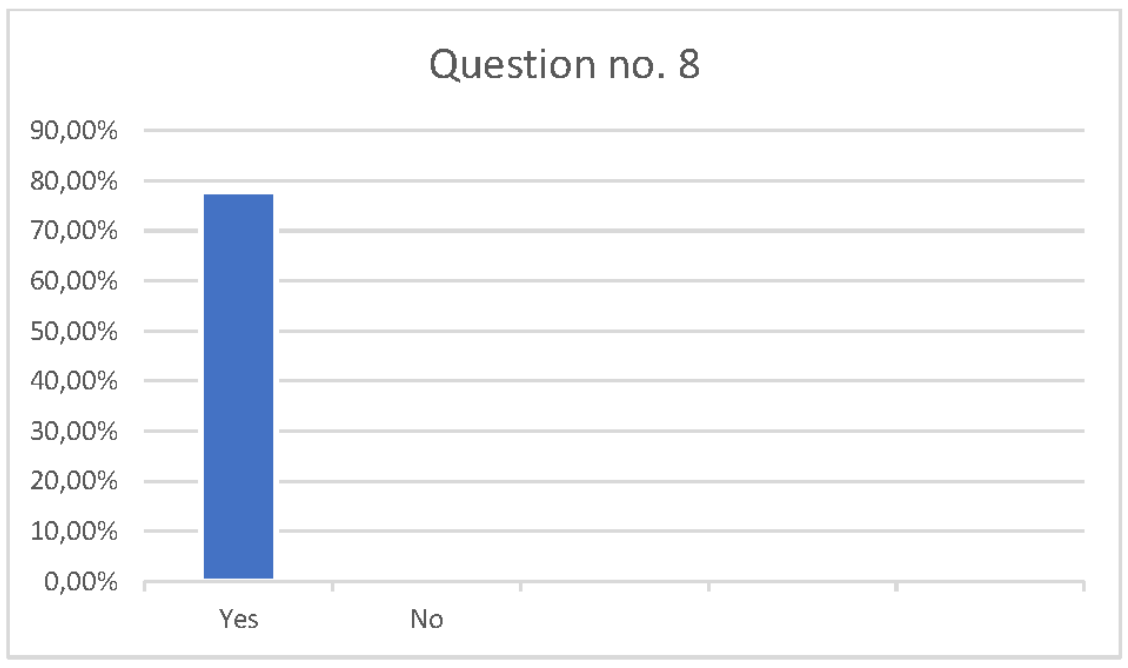

Figure 21: The application of modern technologies in learning English.

Survey results show that $77.93 \%$ of respondents use modern information technologies in learning English, while 22.07\% do not.

Question no. 9: Do you communicate more in English using information technology?

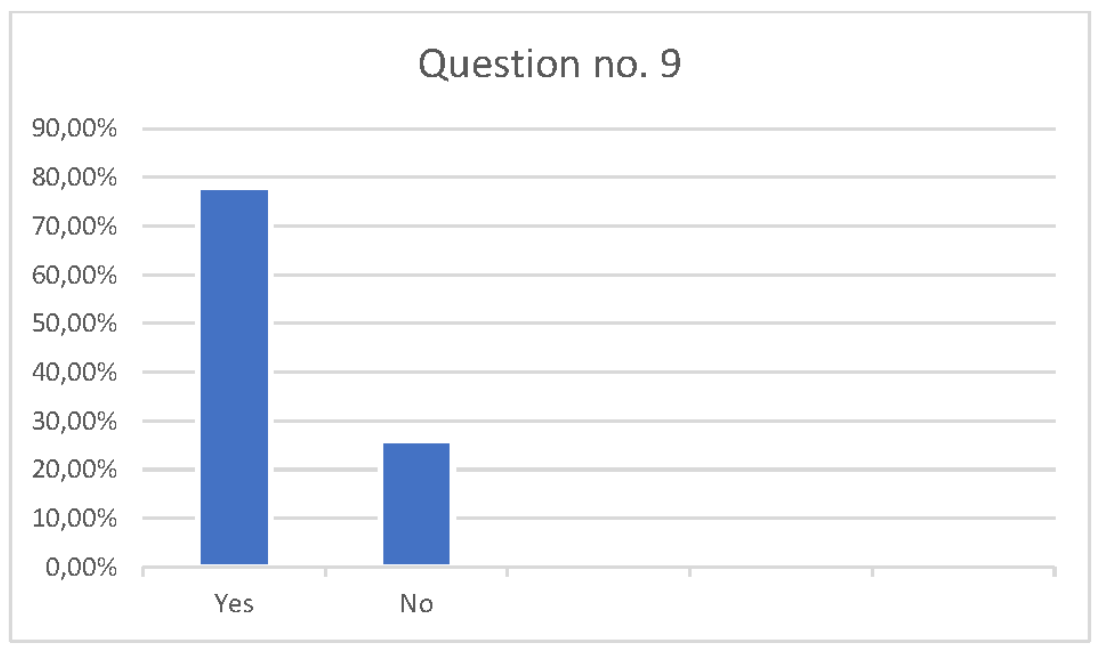

Figure 22: The communication in English using information technology. 
Nihada Delibegović Džanić \& Amila Hasanspahić: Computer assisted language learning in English language classrooms in Bosnia and Herzegovina

According to the survey, $73.79 \%$ of students are indeed more communicating in English with the help of modern information technologies than they normally do without it, while $26.21 \%$ of the respondents did not notice the significant communication potential of modern technologies.

Question no. 10: Are your English language skills improving through the use of the Internet and other information technologies?

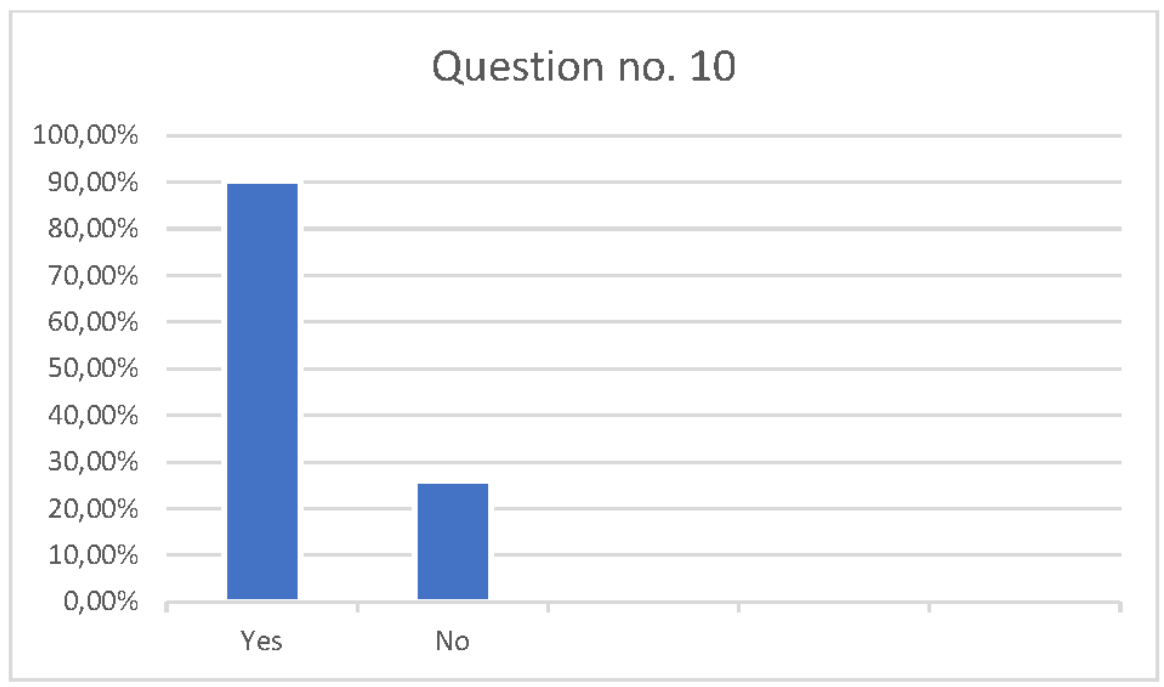

Figure 23: Improvement of English language skills through the use of information technology.

$90.34 \%$ of the students surveyed do see a positive effect of modern information technology on their English language skills, while $9.66 \%$ did not notice a particular impact and results on this issue.

Question no. 11: List your favorite way of learning English with the help of modern information technology.

The surveyed students cite the following as a favorite way of learning English with the help of modern information technology: watching films (especially without subtitles in their native language), reading e-books, listening to songs in English, creating vocabulary and grammar exercises on the Internet, watching news in English, communicating with friends in different parts of the world, using Google translate, playing interactive games, 
Nihada Delibegović Džanić \& Amila Hasanspahić: Computer assisted language learning in English language classrooms in Bosnia and Herzegovina

doing research, watching various shows in English, social networks, playing knowledge tests (Trivia), and taking online English courses.

Question no. 12: Why do you think information technology is useful for learning English?

The students surveyed stated in the survey the following reasons why modern information technologies are so useful for learning English: learning autonomy - they can get information without teacher's help, raise foreign language proficiency, incidentally and easily learn languages, have access to authentic materials, choose their preferred learning channel, create exercises that develop different skills (reading, writing, listening, speaking), access a variety of content and data, quickly translate foreign words, establish active communication and interaction, listen to authentic pronunciation, experience innovative learning, develop critical thinking, different learning methods that suit all types of learners, and their preferred learning channels (auditory, visual, etc.).

Comparing the responses of students coming from different backgrounds, urban or rural, it cannot be said that their answers and attitudes differ significantly. If there are any differences, they are neither significant nor consistent to draw some conclusions about the impact of the environment on the application of technology in English language learning. The reason for this lies in the fact that digitalization is a global phenomenon that is present in every home and is equally accessible to everyone, no matter where one lives, in the village or in the city.

The same is true of the difference between students in different types of schools, for example, between vocational schools and high schools. Based on the study, it is concluded that in every school, regardless of the type of school, some teachers and students use information technology and some do not. The type of school itself did not affect students' attitudes to technology in teaching and other educational purposes. Students from the same school provided different answers regarding their experience with technology, and a similar pattern was repeated in all schools, both in high schools and vocational schools. The vast majority generally had a positive opinion about the use of technology in education, including teaching, regardless of the school they attended, and claimed that they certainly did so in their spare time. Also, students most affirmatively looked at teachers who incorporated technology into their classes, and they rated it equally in high schools and vocational schools. The conclusion is that regardless of the type of education, students prefer technologies in teaching and see a great potential in its application in education, especially in the field of English language learning. This can be considered logical because teens generally follow similar trends, and generally like to use their smartphones, computers and other gadgets. 
Regardless of the milieu they belong to, few have a negative attitude toward something new, especially if it involves modern information technology.

In conclusion, both teachers and students generally see information technology as a motivating factor in the English language learning process, stating that it often facilitates the teaching process. However, for a teacher or student who lacks sufficient computer literacy or does not have a welldefined goal and adequate methodologies of modern information technology it can also be a difficulty and an aggravating factor. This is usually the reason why some teachers and students have not been fully aware of the benefits of this modern mode. Also, it is possible to successfully carry out CALL activities in schools in Bosnia and Herzegovina, taking into account that the activities are performed in accordance with the technological equipment of the school in which they work, in such a way that if they have the opportunity to plan those activities in school, and if not, then only activities adapted to work from home. The research shows that students have access to a computer and the Internet at their homes, and that they are not waiting for the teachers' initiative, but adjust the learning process in accordance with their own needs as 'digital natives' and 21st century students. Teachers should adapt to this change and offer the students what they need and in the way that suits them best. They survey has also shown that activities mentioned are rather common and expected. More can be done in this segment by introducing some new activities so that students do not get bored.

It is important to point out that all these findings could have changed slightly from the moment the data was collected to the present day. Every day, individuals learn about new applications, programs, and activities applicable in English language teaching. It is expected that attitudes are becoming more positive as time goes on, and that the experiences of teachers and students are enriched and receive a positive epilogue.

\section{Conclusion}

In the introduction we stated that the main hypothesis of this paper is that students' results depend on their motivation to learn something, and that, among other things, students can be motivated by the use of modern information technologies in teaching and extracurricular activities. Teachers shared their experiences in working with information technology, presented also the difficulties they faced, and the changes they observed with students. Some even claim that they were able to solve a particular problem by taking the activity outside the classroom walls because it served as a way to overcome shame or traditional norms and motivate them to become more involved. Survey with Bosnian and Herzegovinian teachers shows a similar 
attitude towards motivation. As mentioned earlier, a high percentage $(96.67 \%)$ of the surveyed teachers believe that participation positively correlates with motivation and the majority (93.33\%) are convinced that in CALL learners are highly motivated as CALL always or very often positively influences the development of motivation, enthusiasm and interest in the students. The students then confirm this in their part of the survey. $77.93 \%$ of the students claim that they use a great deal of modern information technologies for the purpose of learning English, and $73.79 \%$ of them note that the positive impact of such learning on their communication skills in English and $90.34 \%$ of them noticed general improvement in their English language proficiency. All this clearly confirms the hypothesis that students' results depend on their motivation to learn something, and that, among other things, students can be motivated by the use of modern information technologies in teaching and extracurricular activities.

Our research also confirmed that learning English using modern information technologies is faster, easier, more interactive, more creative, productive and effective than traditional language learning. As stated earlier, the students recognized the possibility of improving their communication skills thanks to modern information technologies. Also, $94.48 \%$ respondents point out that it is easier, faster and more interesting to learn and work in this way. Teachers also note similar trends, with $86.67 \%$ of them thinking that CALL always or very often makes activities more interesting for students. Likewise, 99\% claim that their students always or very often enjoy activities supported by modern information technologies, compared to activities based on traditional methods. Our third hypothesis is that CALL can be successfully implemented in schools in Bosnia and Herzegovina, regardless of the non-existent or limited technological prerequisites in schools. Often, at teacher training seminars, teachers immediately react saying that they do not have the basic resources and working conditions, because schools in Bosnia and Herzegovina are very poorly equipped with technological aids. However, we want to show exactly opposite, i.e. that it is possible to apply CALL in our schools as well, so that most of these activities and projects are performed outside the classroom. Most of the teachers who participated in the survey $(63.34 \%)$ also claim that their students do not have or have little ability to use modern information technologies in their homes, especially when it comes to children from rural areas of the country. However, the students themselves, who mostly live in the rural areas of our canton, have denied this, given that $87.59 \%$ have a computer at home, and $86.90 \%$ of the students surveyed have a smartphone that can be used in class. It is also important to point out once again that not a single student has stated that they have none of the above. This means that performing CALL activities through homework and outside the classroom can prolong work with students, offer them an adequate alternative, and at least partially repair the 
technological shortcomings of our schools. In this way, CALL would be nicely combined with traditional methods and teaching aids, and easily applied in warm-ups or follow-up activities. Likewise, CALL could serve to all teachers as an extension of the traditional in-class work and the long-soughtafter opportunity to apply the acquired knowledge in a fun and authentic way, for which we usually do not have enough time if we have two or three classes per week and a cumbersome curriculum.

We have shown that CALL is not the only and exclusive method of work, but one in a number of methods, and the results depend directly on the teacher's expertise and ability to successfully combine CALL with other teaching methods and teaching aids.

It all comes down to the fact that the success of such an activity depends on the careful planning and preparation of the teacher. This would mean that any activity we carry out with our students that involves the application of modern information technology must meet and integrate the basic principles of CALL, basic pedagogical and teaching standards of English, and thus be carefully combined with traditional methods of work. CALL is not the only method of teaching English, but just one in a series of methods that can serve a hardworking and enthusiastic teacher to turn their class into a comfortable environment where children both learn and have fun, and work and love to work; an environment where the teacher is more of a helper and guide than a lecturer.

It is believed that children who use modern information technologies also use more complex mental thinking techniques, which could be seen in the practical examples of the use of modern information technologies mentioned in this paper, and are often asked to apply evaluation as the greatest mental level degree, according to Blum's taxonomy.

Generally, teachers should set high criteria and ask students to apply analysis, synthesis and evaluation in order to achieve better results and to prepare them for life after school. However, we often witness that a large number of our students are still at the level of remembering and understanding.

More attention must be paid to the skills that students need to acquire during their education, such as critical thinking skills, problem solving, decision making, goal setting, planning, and active and self-directed learning techniques.

However, it must always be kept in mind that the computer cannot replace the teacher. Meskill (2002: 122) clarifies some of the actions that a computer can and cannot perform. He claims that the computer can evaluate previously entered correct-incorrect answers (for example, multiple-choice or fill-in-the-blanks type of exercises) but cannot evaluate the unexpected answer. Also, the computer can provide immediate feedback (universal and 
immutable), suggestion and encouragement, but not individualized feedback. In addition, the computer can provide authentic information through multimedia materials (texts, videos and audios, images and sounds), but it cannot provide the student with a rich interpretation of meaning characteristic of immediate communication and interaction. A computer can motivate a student to persevere in a task by recording each piece and showing their progress, but it cannot motivate them to engage in deeper and higher quality analysis that is characteristic of spontaneous and immediate human interaction. In conclusion, the computer, like all other modern technologies available, must be treated as an aid, not a cure for all problems. Therefore, the success of CALL is not dependent on the technology itself, but on how CALL is implemented. Proper and moderate use of computers is the key to CALL's success in schools in Bosnia and Herzegovina.

We need to constantly encourage students to be creative, and in order to achieve this, but we, as teachers, must be creative ourselves. Positive results are often proportional to the frustration caused by technical problems or attempts to complete a task within a certain period of time. This process really pays off and is even necessary, but only if the teacher is willing to help students fulfill their full potential in the age of modern information technology.

It is important to point out that this study was conducted before the outbreak of the coronavirus COVID-19 pandemic that forced all teachers and students to use CALL almost overnight. After the pandemic is over, we should research the application of CALL during the pandemic in Bosnia and Herzegovina to see how teachers and students adapted to the new environment and to identify the most significant challenges in terms of adapting both ELT methods and materials.

\section{References}

Beatty, Ken (2003). Teaching and Researching Computer-Assisted Language Learning. New York: Routledge.

Chapelle, Carol A. (2001). Computer Applications in Second Language Acquisition. New York: Cambridge Uniersity Press.

Egbert, Joy (2005). CALL Essentials: Principles and Practices in CALL Classrooms. Alexandria: TESOL.

Egbert, Joy, Elizabeth Hanson-Smith (1999). CALL Environments: Research, Practice, and Critical Issues. Alexandria: TESOL

Levy, Michael (1997). Computer-Assisted Language Learning Context and Conceptualization. New York: Oxford University Press.

Meskill, Carla (2002). Teaching and Learning in Real Time: Media, Technologies, and Language Acquisition. Houston: Athelstan. 
Nihada Delibegović Džanić \& Amila Hasanspahić: Computer assisted language learning in English language classrooms in Bosnia and Herzegovina

Prensky, Marc (2010). Teaching Digital Natives: Partnering for Real Learning. Thousand Oaks: Corwin Press.

Prensky, Marc (2001). Digital natives, digital immigrants. On the Horizon 9(5): 1-6. https://doi.org/10.1108/10748120110424816

Stevanović, Marko (2000). Modeli kreatione nastave. Tuzla: R\&S.

Suzić, Nenad (1999). Interaktiono učenje. Banja Luka: Teacher's Training Center.

\section{Authors' addresses:}

Nihada Delibegović Džanić

Faculty of Humanities and Social Sciences

University of Tuzla

Dr. Tihomila Markovića 1

75000 Tuzla

Bosnia and Herzegovina

e-mail: nihada.delibegovic@untz.ba

Amila Hasanspahić

Behram-bey Madrasa

75000 Tuzla

Bosnia and Herzegovina

e-mail: amila.hasanspahic@gmail.com

Received: April 23, 2020

Accepted for publication: May 4, 2020 